\title{
Use of the chemical permeabilization process in yeast cells: production of high-activity whole cell biocatalysts
}

\author{
ILONA TRAWCZYŃSKA* \\ Faculty of Chemical Technology and Engineering, UTP University of Science and Technology, Bydgoszcz, Poland
}

\begin{abstract}
Yeast cells are popular microorganisms for use in various bioprocesses because of their ability to produce various enzymes. They are also known for their low price. However, the activity of these biocatalysts is limited by cell membrane diffusion. One of the possible solutions to this problem is permeabilization, which makes cell walls and membranes of microorganisms more permeable to allow for easier reagent diffusion, while also maintaining properties of the cells, such as their structure and enzymatic activity. The reusability of permeabilized baker's yeast cells is a major asset that allows them to be successfully used in biotransformation processes. Because of extensive research on this process, numerous procedures have been developed regarding the production of highly active biocatalysts in the form of permeabilized cells. The most commonly used technique is chemical permeabilization. Its effectiveness is based on the activity of various intracellular enzymes: one enzyme or several enzymes simultaneously. Multiple chemical substances, mostly organic solvents and detergents, were analyzed to determine their effectiveness as permeabilizing agents. This review provides a state-of-the-science analysis of substances used as permeabilizing agents for yeast permeabilization.
\end{abstract}

Key words: permeabilization, biocatalyst, yeast cells, microorganisms

\section{Introduction}

In many cases, the elimination of environmentally harmful chemical processes can be achieved using a biocatalyst. For this purpose, enzymes are often used in the form of various preparations such as concentrated solutions, powders, or biomass (Choi et al., 2019; Di Cosimo et al., 2013; Homola et al., 2015; Tozlu et al., 2019). However, the protein structure of enzymes makes them very sensitive to external factors, and they require strictly defined and controlled process conditions. Microbial cells are a rich source of enzymes (Nigam, 2013), and in most cases, extracellular enzymes are being used industrially. Such enzymes produced by microorganisms are secreted into an extracellular medium where they perform their functions (Esteves et al., 2014; Karnwal et al., 2019; Zhenxiao et al., 2016). Cellular enzymes are most often associated with various organelles, and their secretion and purification are costly. Additionally, from the point of industrial technologies, the disadvantage of purified enzymes is their lack of reusability (Al-Najada et al., 2019; Panwar et al., 2017).

Microorganisms, in particular yeasts and bacteria, form a large part of the group of biocatalysts due to significant amounts of intracellular enzymes they produce (Presecki and Vasic-Racki, 2005). The simplicity of their cell culture, nontoxicity, and nonpathogenicity as well as the fact that the cells are an opulent reservoir of enzymes determine the extensive use of yeasts in bioprocesses. Cells, however, hinder substrate access to the enzymatic apparatus because of their compact wall and membrane structure as well as organized transport system. Permeabilization is a solution to this problem as it is a process used to facilitate the diffusion of substrates and reaction products by modifying the cell wall and membrane structures (Matsuzaki, 2019). Permeabilization allows for the movement of substrates and products of catalysis that occurs inside the cells by a cellular machinery. To achieve the highest permeability degree of

\footnotetext{
* Corresponding author: Faculty of Chemical Technology and Engineering, UTP University of Science and Technology, Bydgoszcz, Poland; e-mail: ilona.trawczynska@utp.edu.pl
} 
the cell wall and cellular membranes of microorganisms, it is necessary to choose optimal conditions for permeabilization (e.g., temperature, $\mathrm{pH}$, concentration of permeabilizing agent). These conditions are generally dependent on the enzymes whose intracellular activity is used to determine the degree of permeabilization.

The success of permeabilization can be measured by the activity of intracellular enzymes such as catalase, $\beta$-galactosidase, alcohol dehydrogenase, succinate dehydrogenase, alcohol oxidase, phytase, alkaline and acid phosphatase, glyoxalase I, isocitrate lyase, and others. According to Presecki et al. (2007), permeabilization also removes most of the low-molecular-weight cofactors from the cell, thus minimizing the unwanted side reactions catalyzed by enzymes that need cofactors. In some methods, undesirable phenomena of the permeabilization process occur, i.e., the leaking of enzymes from the permeabilized cells. Therefore, one of the essential elements of permeabilization is preventing enzymes from leaking out as it would significantly decrease the effectiveness of biocatalysts (Flores et al., 1994).

In the present article, developments in the methods of increasing cell membrane permeability to identify commercially interesting enzymatic activities in yeast cells are discussed. It provides a state-of-the-science analysis of chemical substances used in the permeabilization process of yeast cells. The need for such an analysis resulted from the lack of consolidated knowledge necessary to develop a biocatalytic process using whole cells, such as biocatalyst screening, biocatalyst optimization, medium, and reaction condition optimization.

The cells used in a catalytic process after applying permeabilization can easily be separated from the reaction environment and used again, generally without the fear of a greater loss in enzymatic activity (Berlowska et al., 2006; Venkateshwaran et al., 1999).

The most frequently applied technique is chemical permeabilization, which is the most effective one in most circumstances. Chemical permeabilization using organic solvents, antibiotics, thionins, surfactants, chaotropic agents, and chelates has been reported in recent years (Cortez and Roberto, 2010; Koli et al., 2016: Panduric et al., 2017; Takatsume et al. 2014; Voget, 2018; Yan et al., 2017). The method based on use of chemicals to permeabilize microorganisms has been applied to both harvested cells and growing cells (Naglak and Wangt, 1992; Noubhani et al., 2000). Nevertheless, the applica- tion of chemical permeabilization during fermentation is more difficult because of the effects of chemicals on cell growth and viability. Changes in osmotic pressure have also been used to permeabilize microorganisms (Crotti et al., 2001; Tan et al., 2011). Permeabilization by osmotic shifts is fairly mild because it avoids treatments of cells with organic solvents and/or detergents, which might denature or change the properties of the assayed enzymes. The method may be advantageous, for example, in rapid screening of enzyme inhibitors or in assays of a large number of different cell samples. Although it is a universal method, it does not produce better results than chemical permeabilization (Chow and Palecek, 2004; Nayak et al., 2005). In addition, certain difficulties occur when the technology is transferred to the industrial scale (Liu et al., 2016). The complexity of this method, handling large amounts of osmolyte solutions, and the need to maintain low temperature pose a big challenge (Sestak and Farkas, 2001).

An increase in cell permeability can also be achieved using an appropriate magnetic field of an appropriate strength; this method is called electropermeabilization (Novickij et al., 2018; Stirke et al., 2014; Teissie et al., 2005). Additionally, a few studies describe the attempts to perform enzymatic permeabilization (Naglak and Wangt, 1992; Zlotnik et al., 1984). Some researchers also evaluated periodic freezing and thawing of microbial cells as a method of permeabilization (Seip and Di Cosimo, 1992). Electropermeabilization, enzymatic permeabilization, and freezing and thawing are methods that cause large damage to the cell wall structure. Hence, they are mainly used as techniques for releasing proteins from yeast cells.

The aim of this paper is to review the potential of some chemical substances for increasing the permeability of yeast cell membranes. The advantages and drawbacks of the use of different detergents and organic solvents are summarized by considering the intracellular enzyme activity and the leakage of the enzyme from the cells. The identification of a suitable permeabilizing agent is very important to create efficient biocatalysts in the form of permeabilized yeast cells with high enzyme activity. Using such biocatalysts is an ecological and efficient alternative to industrial processes, and it reduces the use and handling of many toxic compounds and solvents. 


\section{Chemical permeabilization}

In 1982, Felix compiled a path-breaking set of chemical substances that were effective in the permeabilization of prokaryotic and eukaryotic cells (Felix, 1982). He was the first to indicate that the choice of the permeabilization method is highly dependent on the composition of cell walls and membranes as well as their structure. He also highlighted the importance of sterols in fungal cells, which affect the fluidity and plasticity of cytoplasmic membranes. The author suggested that removing fat components from cell wall permeabilization agents triggers the disruption of cell membrane structure, thereby increasing its permeability. The mechanism of permeabilization is still unknown, and most researchers consider Felix's assumptions to be valid (Fenton, 1982; Koley and Bard, 2010; Kumari et al., 2011; Rodriguez-Colinas et al., 2011; Yadav et al., 2014).

\section{Detergents}

Detergents are most commonly used in the chemical permeabilization of yeast cells. They are amphiphilic molecules as they possess hydrophobic and hydrophilic parts in their structures. Detergents can be divided into three main groups: nonionic, ionic, and zwitterionic. Nonionic detergents do not have any charge in the area of the hydrophilic head as the ionic ones have. The third group, zwitterionic detergents, are substances that simultaneously have positive and negative charges, but their net charge is zero.

Table 1 and Table 2 present the research on the use of detergents in the permeabilization of yeast cells. Most of the detergents used are toxic and nonbiodegradable, which hinders their application especially in the feed and food processing industry. Among the wide range of compounds, cetyltrimethylammonium bromide (CTAB) and Triton X-100 are usually selected for permeabilization.

\section{CTAB}

CTAB is a cationic surfactant that belongs to the group of quaternary ammonium salts (He et al., 2017; Llombart et al., 2019). This very popular compound in the field of molecular biology of plants has become the object of interest in the study on the permeabilization process of baker's yeast and bacteria (He et al., 2010; Panduric et al., 2017; Presecki and Vasic-Racki, 2005;
Presecki et al., 2007; Rajagopal et al., 2014: Sekhar et al. 1999; Venkateshwaran et al. 1999; Wang et al., 2019). For increasing the permeability of cell membranes, $\mathrm{CTAB}$ is usually used at room temperature, and the concentration ranges between $0.1 \%$ to $2 \%$ for $30 \mathrm{~min}$.

\section{Permeabilization of Saccharomyces cells}

$\mathrm{CTAB}$ is widely used in the permeabilization of Saccharomyces cells because it has extreme effectiveness as a permeabilizing agent. The usefulness of CTAB in the permeabilization process of $S$. cerevisiae yeast is measured based on the activity of various intracellular enzymes (Table 1).

The use of $S$. cerevisiae as a source of catalase that decomposes hydrogen peroxide into oxygen and water was studied by Sekhar et al. (1999) and Venkateshwaran et al. (1999). The application of CTAB on cells to increase their permeability enabled a 3,200-fold increase in the activity of catalase. The enzyme in permeabilized cells was more stable against self-inactivation during catalysis than the enzyme in cell-free extract and purified catalase. Unfortunately, during the storage of cells permeabilized with $\mathrm{CTAB}$, catalase is slowly released from the cells, which is an undesired feature of this method. How to counteract this process is described later in the article.

Additionally, $S$. cerevisiae cells were permeabilized to increase the activity of intracellular enzymes such as fumarase which catalyzes the conversion of fumaric acid to malic acid (Presecki and Vasic-Racki, 2005; Presecki et al., 2007). Permeabilization of cells possessing an increased fumarase activity was performed in relatively mild conditions. The maximum, i.e. a fourfold increase, in fumarase activity was possible after the treatment with $\mathrm{CTAB}$ at a low concentration $(0.2 \%)$ for a short period of time (5 min) (Presecki and Vasic-Racki, 2005; Presecki et al., 2007).

\section{Permeabilization of yeast cells of other genus}

Permeabilization using CTAB also provided good results with yeast cells of the genus Rhodotorula, Pichia, and Kluyveromyces (Table 2). The effect of $0.4 \%$ detergent on $P$. pastoris (Tan et al., 2007) and $R$. gracilis (Upadhya et al., 1999) allowed to produce highly active biocatalysts for the conversion of phenylalanine to phenylpyruvate. This bioconversion was catalyzed by an amino acid oxidase and catalase located inside the permeabilized cells. 
Table 1. Enzymes whose activity was determined in studies on the permeabilization of Saccharomyces cells by CTAB

\begin{tabular}{l|l}
\hline \multicolumn{1}{c|}{ Enzyme } & \multicolumn{1}{c}{ Reference } \\
\hline \multirow{2}{*}{ Catalase } & $\begin{array}{l}\text { Sekhar et al. (1999); } \\
\text { Venkateshwaran et al. (1999) }\end{array}$ \\
\hline \multirow{2}{*}{ Fumarase } & Presecki and Vasic-Racki (2005) \\
\cline { 2 - 2 } Alcohol dehydrogenase & Presecki et al. (2007) \\
\hline Alcohol dehydrogenase, hexokinase, glucose-6-phosphate dehydrogenase & Norouzian et al. (2003) \\
\hline
\end{tabular}

Table 2. Enzymes whose activity was determined in studies on the permeabilization of yeast cells by CTAB

\begin{tabular}{|c|c|c|}
\hline Enzyme & Yeast & Reference \\
\hline \multirow{5}{*}{ Catalase, amino acid oxidase } & \multirow{2}{*}{ Rhodotorula gracilis } & Upadhya et al. (1999) \\
\hline & & Upadhya et al. (2000) \\
\hline & \multirow{2}{*}{ Pichia pastoris } & Tan et al. (2007) \\
\hline & & Tan et al. (2011) \\
\hline & Kluyveromyces marxianus & Kostova et al. (2008) \\
\hline \multirow{3}{*}{$\beta$-galactosidase } & \multirow{3}{*}{ Kluyveromyces fragilis } & Joshi et al. (1987) \\
\hline & & Joshi et al. (1989) \\
\hline & & Bachhawat et al. (1996) \\
\hline $\begin{array}{l}\text { Alcohol dehydrogenase, } \\
\text { glucose-6-phosphate dehydrogenase }\end{array}$ & brewer's yeasts & Yu et al. (2007) \\
\hline $\begin{array}{l}\text { Alcohol oxidase, formaldehyde dehydrogenase, } \\
\text { formate dehydrogenase }\end{array}$ & Pichia pinus & Alamae and Jarviste (1995) \\
\hline
\end{tabular}

The use of CTAB at a low concentration $(0.2 \%)$ in the permeabilization of brewer's yeast cells increased the activity of alcohol dehydrogenase and glucose-6-phosphate dehydrogenase (Yu et al., 2007). In permeabilized cells, the enzymatic activity was $525 \mathrm{U}$, which was 7.9-fold higher than that in nonpermeabilized cells. Thus, the prepared biocatalyst was successfully used in the presence of allyl bromide for the bioconversion of ethyl 4-chloro-3-oxobutanoate to ethyl 4-chloro-3-hydroxybutanoate.

\section{Difficulties associated with the use of CTAB in the permeabilization process}

CTAB shows a high efficiency in the process of permeabilization, but its use is also associated with negative effects. Numerous researchers have noted the leakage of the enzyme from the inside of cells during storage (Alamae and Jarviste, 1995; Kostova et al., 2008; Tan et al., 2011; Upadhya et al., 2000). The use of CTAB solutions in the permeabilization of methylotrophic yeast Pichia pinus is associated with the release of enzymes from the cells after less than 1 day of storage, even at a very low concentration of $0.1 \%$ (Alamae and Jarviste, 1995). The storage of a permeabilized suspension at $8^{\circ} \mathrm{C}$ resulted in a marked leakage of dehydrogenases, but not of alcohol oxidase, from the cells. Kostova et al. (2008) and Upadhya et al. (2000) attempted to resolve this issue. It has been demonstrated that by applying CTAB to $R$. gracilis cells, the activity of their intracellular amino acid oxidase and catalase can be increased by 90 and 15 times, respectively (Upadhya et al., 2000). The problem of a partial release of both enzymes due to CTAB treatment was resolved using glutaraldehyde at $0.2 \%$ concentration. This crosslinking agent allowed for successful immobilization of amino acid oxidase and catalase inside the cells as the reported half-life period for oxidase and catalase was 120 and 155 days, respectively (Upadhya et al., 2000). These results were incredibly high compared to those for CTAB-permeabilized cells but without glutaraldehyde crosslinking. The half-life period for those enzymes was approximately 2 days. The 
immobilization of enzymes within the cells by glutaraldehyde, which causes cross-linking of the enzymes with other intracellular components or to cell debris, maintains enzymes in the natural microenvironment, rendering them more stable. Importantly, glutaraldehyde crosslinking as a method of diminishing the leakage of the enzyme has been debated. A group of Chinese researchers (Tan et al., 2011) did not achieve satisfactory results that could be compared to those presented by Upadhya et al. (1999). In CTAB-permeabilized cells, crosslinked amino acid oxidase had a half-life period of only 15.5 days (compared to 120 days in the study of Upadhya et al. (2000)). Hence, the application of glutaraldehyde crosslinking led to only a slight increase in the half-life (by 1 day) of the enzymes compared to that in permeabilized cells unexposed to a crosslinking agent.

\section{Triton X-100}

Triton X-100, a polyoxyethylene octyl phenyl ether (ionic surfactant), is a chemically inert detergent used in the permeabilization processes of various microorganisms: yeast (Chen etal., 1992; Chow and Palecek, 2004; Kaur and Satyanarayana, 2010), bacteria (Ge et al., 2015; Kinosita et al., 2018; Shin et al., 2016), and fungi (Chelico and Khachatourians, 2003; Villa et al., 2009).

\section{Permeabilization of Saccharomyces cells}

Triton X-100 has been applied to permeabilize $S$. cerevisiae cells in the form of a solution with concentration not greater than $1 \%$. The use of Triton X-100 alleviates the permeability barrier of the cell membranes, thereby permitting free mobility of substances, including substrates and products, across cell membranes. Table 3 presents enzymes whose activity was determined in the studies on Triton X-100 permeabilization of $S$. cerevisiae cells.

When $S$. cerevisiae cells were treated with Triton $\mathrm{X}-100$ to extract the cell membrane, $\beta$-galactosidase activity in the permeabilized cells was approximately $40 \%$ of the activity of the protein in the cell extract (Chow and Palecek, 2004). The attempts to increase the efficiency of the permeabilization process were unsuccessful. As reported, the $\beta$-galactosidase activity obtained after the pretreatment of $S$. cerevisiae cells with $100 \%$ ethanol or by using an osmotic shock prior to the addition of Triton X-100 did not significantly differ from the activity achie-
Table 3. Enzymes whose activity was determined in studies on the permeabilization of $S$. cerevisiae cells by Triton X-100

\begin{tabular}{l|l}
\hline \multicolumn{1}{c|}{ Enzyme } & \multicolumn{1}{c}{ Reference } \\
\hline B-galactosidase & Chow and Palecek (2004) \\
\hline Alcohol dehydrogenase & Laouar et al. (1996) \\
\hline Succinate dehydrogenase & Berłowska et al. (2006) \\
\hline
\end{tabular}

ved using the detergent itself. The optimum concentration range of Triton X-100 to achieve the highest $\beta$-galactosidase activity in permeabilized $S$. cerevisiae cells varied from 0.3 to $1.0 \%$ (Chow and Palecek, 2004). In comparison, the optimum concentration of the detergent for Yarrowia lipolytica cells (Galabova et al., 1996) ranged from 0.1 to $0.2 \%$. This confirms that permeabilization conditions are strongly related to the cell structure and its morphology.

The effectiveness of Triton X-100 in the permeabilization of $S$. cerevisiae cells was also compared to that of another surfactant, namely Pluronic F-68 (Laouar et al., 1996). This compound is used as an antifoaming and protective agent for eukaryotic cell cultures (Handa-Corrigan et al., 1992; Lowe et al., 1993; Papoutsakis, 1991). The various physiological effects exerted by Pluronic F-68 on yeast cells are largely explained by its interaction with the cell membrane (King et al., 1991). It can also cause a significant increase in the permeability of cell membranes (Laouar et al., 1996). It is assumed that this effect is related to transitional membrane pores caused by the formation of molecular aggregates of the surfactant in the cell membrane (King et al., 1991). Unlike the addition of Triton X-100, Pluronic F-68 does not affect the growth kinetics of $S$. cerevisiae. Triton X-100 also exhibits inhibitory effects at the initial stages of the logarithmic growth of the microorganisms as it slows down their aging process (Laouar et al., 1996). Nevertheless, Triton X-100 provides a considerably higher increase in the intracellular activity of alcohol dehydrogenase, which proves its superiority over Pluronic F-68 in the process of permeabilization.

\section{Permeabilization of yeast cells other than Saccharomyces by Triton X-10O}

Triton X-100 has been proven to be effective as a permeabilizing agent in the permeabilization of yeast cells from the genus Pichia and Yarrowia (Table 4). Chen 
Table 4. Enzymes whose activity was determined in studies on the permeabilization of yeast cells by Triton X-100

\begin{tabular}{l|l|l}
\hline \multicolumn{1}{c|}{ Enzyme } & \multicolumn{1}{c|}{ Yeast } & \multicolumn{1}{c}{ Reference } \\
\hline Alcohol oxidase & Pichia pastoris & Chen et al. (1992) \\
\hline Phytase & Pichia anomala & Kaur and Satyanarayana (2010) \\
\hline Alkaline and acid phosphatase & Yarrowia lipolytica & Galabova et al. (1996) \\
\hline
\end{tabular}

et al. (1992) were the first group to prove the effectiveness of Triton X-100 in combination with glycine in the permeabilization process of $P$. pastoris cells with abundant alcohol oxidase. The compound altered the cell membrane structure, thereby increasing the alcohol oxidase activity, but without causing the enzyme leakage outside the cell.

$P$. anomala is a yeast species rich in phytase (Joshi and Satyanarayana, 2014; Kaur and Satyanarayana, 2010). This enzyme accelerates the degradation of phospho-monoester bonds from phytic acid. Salts of phytic acids are mainly found in cereals or legumes and are very poorly digested by monogastric animals (without bacterial flora) (Greiling et al., 2019; Mesina et al., 2019; Sommerfeld et al., 2019). The use of Triton X-100 in the permeabilization of $P$. anomalayeast cells enabled to increase the phytase activity by $15 \%$ as compared to that in nonpermeabilized cells (Kaur and Satyanarayana, 2010).

Difficulties associated with the use of Triton X-10O in the permeabilization process

Triton X-100 is a very effective permeabilizing agent (Galabova et al., 1996; Mattei et al., 2017), but the cells treated with this detergent cannot be used again due to their partial disintegration (Berłowska et al., 2006; Manocha and Gaikar, 2006). It was found that the use of $0.5 \%$ Triton X-100 released approximately $40 \%$ of proteins from Aspergillus niger cells (Manocha and Gaikar, 2006). Microscopy images presented by Berłowska et al. (2006) are another proof of succinate dehydrogenase leakage related to the changes in cell morphology caused by Triton X-100. Among the five different chemical compounds tested by Berlowska et al. (2006), digitonin was the only one that effectively influenced the permeabilization process of $S$. cerevisiae cells without negatively affecting their cell wall structure. However, the problem of the leakage of protein substances from Triton X-100permeabilized cells does not apply to all enzymes. To detect the enzyme that may have leaked from Triton X-100-permeabilized S. cerevisiaecells, the galactosidase activity in the supernatant from the cells following permeabilization was measured (Chow and Palecek, 2004). No detectable enzyme activity outside the permeabilized cells was found. The results of Galabova et al. (1996) are another example of difficulties associated with the use of Triton X-100 in the permeabilization process. The maximal permeabilization of $Y$. lipolytica cells was achieved using $0.1-0.2 \%$ of Triton X-100. Unfortunately, $20 \%$ of the total protein was released into the supernatant by Triton X-100 treatment. Based on the scanning electron micrographs of permeabilized yeast cells, a disruption of the cell wall in certain zones, especially in the zones of bud scars of cells, was observed.

\section{Other detergents}

Among the other detergents used in the permeabilization of yeast cells, N-lauroylsarcosine and its sodium salt (sarkosyl) are worthy of attention (Abraham and Bhat, 2008; Voget, 2018; Yadav et al., 2014). These nontoxic and biodegradable compounds are cationic surfactants that easily increase the permeability of baker's yeast cell walls and membranes (Abraham and Bhat, 2008). As reported by Abraham and Bhat (2008), N-lauroylsarcosine enabled a 350-fold increase in the intracellular catalase activity. In the permeablization of $S$. cerevisiae, it was observed that sodium lauroyl sarcosinate was more effective than chloroform, toluene, Brij-35, CTAB, and dimethyl sulfoxide (DMSO) (Kippert, 1995). According to Yadav et al. (2014), these detergents also improve the permeability of $K$. marxianus cells. N-lauroylsarcosine significantly improves the intracellular activity of $\beta$-galactosidase.

To permeabilize yeast cells, ammonium salts, e.g., benzalkonium chloride - a cationic surfactant commonly used for disinfection - has also been used (Gough et al., 2001). Its effect on recombinant $P$. pastoris cells ena- 
bled a 10-fold increase in the intracellular glycolane oxidase activity. Benzalkonium chloride was proved to be a better permeabilizing agent than CTAB, Triton X-100, and Tween 80 (Gough et al. 2001).

\section{Organic solvents used for the permeabilization of yeast cells}

Organic solvents, as compared to detergents, are also commonly used in methods aimed to increase the permeability of cell membranes (Fontes et al., 2001; Kondo et al., 2000; Lee et al., 2004; Liu et al., 1999; Liu et al., 2000; Panesar et al., 2007a; Panesar et al., 2007b; Panesar et al., 2011; Rodriguez-Colinas et al., 2011; Trawczyńska and Wójcik, 2014, 2015). Several aspects mentioned above and related to the use of detergents in permeabilization processes make organic solvents much more competitive in terms of cost and ease of application (Rosinha Grundtvig et al., 2018). Alcohols are the most commonly used solvents in the permeabilization of yeast cells. Moreover, some studies attempted to increase the permeability of cell membranes by using toluene (Choudary and Rao, 1976; Choudary, 1984), a mixture of toluene and ethanol (Serrano et al., 1973), benzene (Panesar et al., 2007a; Panesar et al., 2007b), ethyl acetate (Liu et al., 1999), ethyl ether (Seip and Cosimo 1992), chloroform, or acetone (Kumari et al., 2011; Trawczyńska and Wójcik, 2014).

\section{Alcohols}

Tables 5 and 6 present studies on the use of alcohol in the permeabilization of yeast cells. The effectiveness of alcohols vis a vis other chemicals used for the permeabilization of yeast has often been compared. The results and conclusions of selected items have been approximated and reported later in the article.

\section{Permeabilization of Saccharomyces cells}

Alcohols are effective agents in the permeabilization of $S$. cerevisiae cells (Table 5 ). They tend to be better than detergents, depending on the type of the intracellular enzyme whose activity is assayed. Another advantage of alcohol is the fact that the permeabilization process using alcohol does not disturb the flocculation ability of yeast (Kondo et al., 2000). This is one of the important characteristics of yeast strains used in industrial applications because flocculent yeast can be separated easily. Proteins involved in flocculation are highly resistant to alcohol permeabilization.
Trawczyńska and Wójcik $(2014,2015)$ confirmed the effectiveness of methanol, ethanol, 1-propanol, and 2-propanol as agents used to increase the permeability of baker's yeast cell walls and membranes against reaction reagents catalyzed by their intracellular catalase. The best result was achieved when $53.7 \%$ of isopropyl alcohol was used for $40 \mathrm{~min}$ at a temperature of $15.6^{\circ} \mathrm{C}$. The maximum value of the catalase activity was $6.188 \mathrm{U} / \mathrm{g}$ wet wt. This result is slightly different from the overall activity of the yeast catalase ( $6.500 \mathrm{U} / \mathrm{g}$ wet wt.), which indicates the possibility of free access of hydrogen peroxide to the enzymatic apparatus. The maximum value of the catalase activity was approximately 60 times higher than the catalytic activity of yeast not treated by the permeabilization process (Trawczyńska and Wójcik, 2014). The use of the two other alcohols also allowed to achieve satisfactory results in terms of optimal conditions, wherein ethanol and 1-propanol increased the catalase activity by 47 and 40 times, respectively (Trawczyńska and Wójcik, 2015).

$S$. cerevisiae cells are rich not only in previously described catalase, fumarase, or dehydrogenases but also in several other enzymes, including glyoxalase I (Bankapalli et al., 2015; Liu et al., 1999; Panesar et al., 2007a) and isocitrate lyase (Liu et al., 2000; Liu et al., 2014). Glyoxalase I catalyzes the conversion of methylglyoxal to S-lactoylglutathione in the presence of glutathione. The initial S-lactoylglutathione production rates of isopropyl alcohol-permeabilized cells were 1.5-2.5 times higher than those of glyoxalase I in cells prepared by the ethyl acetate method from the same amount of cells (Liu et al., 1999). It has been shown that among the first three alcohols of the homologous series, i.e., methanol, ethanol, and 2-propanol, the most effective permeabilizing agent for $S$. cerevisiae cells was the last one. Permeabilization of intact $S$. cerevisiae cells using 2-propanol enabled 582 times higher production of S-lactoglutathione. Moreover, the use of cells permeabilized with alcohol increased the process rate by $1.5-2.5$ times compared to the use of glyoxalase extract acquired from the same amount of yeast. It is noteworthy that the production rate of S-lactoglutathione was equally high for cells permeabilized with ethanol. The amount of glyoxalase released outside the cell during this process by using alcohol was nonsignificant. Therefore, in this case, the high activity of permeabilized cells was attributed only to the decrease of the membrane's permeability threshold (Liu et al., 1999). 
Table 5. Enzymes whose activity was determined in studies on the permeabilization of $S$. cerevisiae cells by alcohol

\begin{tabular}{|c|c|c|}
\hline Alcohol & Enzyme & Reference \\
\hline $\begin{array}{l}\text { Methanol, ethanol, } \\
\text { 1-propanol, 2-propanol }\end{array}$ & catalase & $\begin{array}{l}\text { Olczak et al. (2010) } \\
\text { Trawczyńska and Wójcik (2014) } \\
\text { Trawczyńska and Wójcik (2015) } \\
\text { Trawczyńska et al. (2018) } \\
\text { Trawczyńska et al. (2019) } \\
\text { Trawczyńska (2020a) } \\
\text { Trawczyńska (2020b) }\end{array}$ \\
\hline Ethanol, 2-propanol & glyoxalase & Kondo et al. (2000) \\
\hline Methanol, ethanol, 2-propanol & glyoxalase & Liu et al. (1999) \\
\hline Ethanol, 2-propanol & glyoxalase, isocitrate lyase & Liu et al. (2000) \\
\hline
\end{tabular}

Table 6. Alcohols used to permeabilize Kluyveromyces cells to increase $\beta$-galactosidase activity

\begin{tabular}{l|l}
\hline \multicolumn{1}{c|}{ Alcohol } & \multicolumn{1}{c}{ Reference } \\
\hline $\begin{array}{l}\text { Ethanol, 2-propanol, } \\
\text { 1-propanol, 1-butanol }\end{array}$ & Panesar et al. (2007a) \\
\hline \multirow{4}{*}{ Ethanol } & Fontes et al. (2001) \\
\cline { 2 - 2 } & Lee et al. (2004) \\
\cline { 2 - 2 } & Rodriguez-Colinas et al. (2011) \\
\cline { 2 - 2 } & Panesar et al. (2007b) \\
\cline { 2 - 2 } & Panesar et al. (2011) \\
\hline
\end{tabular}

The possible influence of alcohol on the activities of assessed enzymes has also been evaluated (Liu et al., 2000). For instance, glyoxalase showed a constant activity for $4 \mathrm{~h}$ when placed in $95 \%$ ethanol and $40 \% 2$-propanol solutions. However, isocitrate lyase was incredibly sensitive to alcohol, and within a few seconds, its activity decreased significantly (Liu et al., 2000). Hence, the activity of the enzymes in alcohol permeabilization processes is highly dependent on the characteristics of the enzymes themselves.

As mentioned before, the increase in the degree of permeability of cell walls and membranes of microorganisms is affected not only by the type of the permeabilizing agent but also by the conditions of the process. This includes temperature, the concentration of the chemical substance, and the duration of the process. While studying the permeabilization of $S$. cerevisiae cells by using alcohol for reaction reagents catalyzed by glyoxalase I, it was found that a low temperature $\left(4^{\circ} \mathrm{C}\right)$ facilitates to increase the effectiveness of the process. The enzyme activity was 345,326 , and $340 \mathrm{mmol} / \mathrm{min} / \mathrm{g}$-wet cell for permeabilization with methanol, ethanol, and isopropyl alcohol, respectively (Liu et al., 1999). It has also been shown that as the temperature increases $\left(25^{\circ} \mathrm{C}\right)$, lower concentrations of alcohol (20\%) should be used accordingly. The influence of alcohol concentrations on the permeabilization process, assessed by the initial reaction rates catalyzed by glyoxalase I and isocitrate lyase, was very similar (Liu et al., 2000). However, the highest effectiveness of the permeabilization process, i.e., the highest permeability rate of the cells was achieved using $40 \%$ solution of 2-propanol for both enzymes. The influence of the duration of the permeabilization process on the activity of the biocatalyst depends on the enzyme of interest because extending the duration of the permeabilization process up to 50 minutes, results in an increase in the initial rate for the reaction catalyzed by S. cerevisiae cells with the overproduction of glyoxalase. Continuation of the process resulted in a slower reaction rate.

\section{Permeabilization of yeast cells of other species using alcohols}

Alcohols are also effective permeabilizing agents in the permeabilization of Kluyveromyces yeast which is rich in $\beta$-galactosidase (Fontes et al., 2001; Lee et al., 2004; Panesar et al., 2007a; Panesar et al., 2007b; Panesar et al., 2011; Rodriguez-Colinas et al., 2011) - Table 6 , an enzyme catalyzing the degradation of the disaccharide lactose that is often intolerable to humans. The increase in the intracellular activity of Kluyveromyces $\beta$-galactosidase was possible because of permeabilization with ethanol, 1-propanol, 2-propanol, and 1-butanol. However, the best results (1510 IU/g-dry cell) were achieved for ethanol. A 50\% solution of this alcohol was more ef- 
fective than acetone, toluene, benzene, and Triton X-100 (Panesar et al., 2007a; Panesar et al., 2007b).

Panesar et al. (2007a) indicated that temperature and alcohol concentrations are the key factors influencing the permeabilization process of Kluyveromyces. They also rejected the suggestion that the duration of the process influences its effectiveness. The $\beta$-galactosidase activity increased up to $1500 \mathrm{IU} / \mathrm{g}$-dry cell along with the increase in temperature up to $25^{\circ} \mathrm{C}$ after the permeabilization of Kluyveromyces using ethanol. When the temperature increased further, the enzymatic activity significantly decreased. At temperatures above $35^{\circ} \mathrm{C}$, the enzyme became inactive. This phenomenon has been explained by a partial enzyme deactivation at high temperatures (Panesar et al., 2007a; Panesar et al., 2007b).

Kluyveromyces cells permeabilized using ethanol can also be used as biocatalysts with an increased $\beta$-galactosidase activity in other bioprocesses, e.g., enzymatic synthesis of lactulose from lactose and fructose (Lee et al., 2004). The activity of the intracellular enzyme was compared with that of various industrial $\beta$-galactosidases; however, the greatest production efficiency of lactulose was achieved with a biocatalyst in the form of whole cells. Ethanol-permeabilized Kluyveromyces cells enabled 1.3-fold increase in product concentration and 2.1-fold increase in effectiveness as compared to nonpermeabilized cells. Other studies have indicated that further modifications (e.g., lyophilization, immobilization) of this type of biocatalysts are possible (Kaur et al., 2009; Panesar et al., 2011; Rodriguez-Colinas et al., 2011).

\section{Comparison of alcohols with other organic solvents} as permeabilization agents

In addition to alcohols, esters (ethyl acetate), ketones (acetone), chlorinated alkanes (chloroform), and aromatic compounds (benzene, toluene) were tested to evaluate their effectiveness in the process of the permeabilization of cells (Panesar et al., 2007b; Kumari et al., 2011). In most cases, these studies proved that alcohols were the most effective permeabilizing agents (Trawczyńska and Wójcik, 2014, 2015).

Two recent studies (Trawczyńska and Wójcik, 2014, 2015) present the influence of most of the abovementioned compounds on the permeability of baker's yeast cells. Permeabilization was used to increase the activity of the yeast intracellular catalase. According to the graph (Fig. 1), the highest enzyme activity was obtained after permeabi-

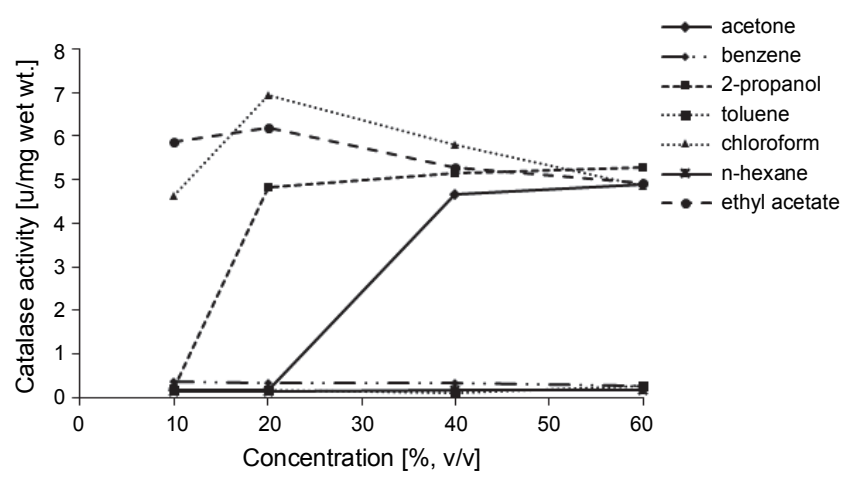

Fig. 1. Effect of permeabilizing agent concentration on the permeabilization of baker's yeast cells

(Trawczyńska and Wójcik, 2014, 2015)

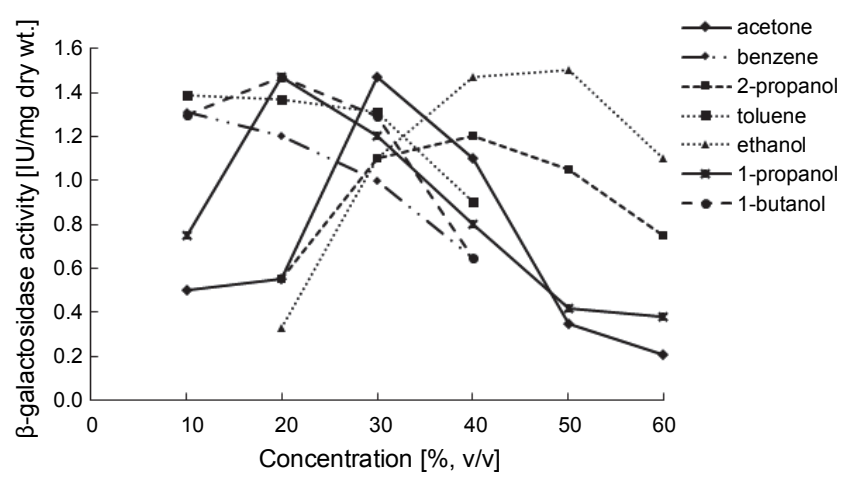

Fig. 2. Effect of permeabilizing agent concentration on the permeabilization of $K$. marxianus cells (Kumari et al., 2011)

lization with acetone ( $\sim 4500 \mathrm{U} / \mathrm{g}$-wet cell), chloroform ( $7000 \mathrm{U} /$ g-wet cell), 2-propanol ( $\sim 5500 \mathrm{U} /$ g-wet cell), and ethyl acetate ( $\sim 6000 \mathrm{U} / \mathrm{g}$-wet cell).

A similar comparison of permeabilizing agents was conducted for $K$. marxianus yeast cells (Kumari et al., 2011) (Fig. 2) to increase the activity of intracellular $\beta$-galactosidases. A high degree of enzyme activity (1.5 U/mg-dry cell) was observed upon permeabilization with ethanol, 1-propanol, 2-propanol, and acetone.

Thus far, on the basis of the presented research results, we can conclude that permeabilization using organic solvents is very effective, hence making it very popular. However, while using organic solvents, one should also consider the fact that some of them (toluene, ethyl ether) are difficult to be completely removed after the permeabilization process (Seip and Di Cosimo, 1992). The undisputed advantages of cell permeabilization with alcohol are its low cost and biodegradability of post-production wastes. Additionally, the process conducted under mild conditions allows to obtain biocatalysts with 
high enzymatic activity (Olczak et al., 2010; Trawczyńska and Wójcik, 2014). 1-Propanol and 2-propanol were mainly used in alcohol permeabilization of yeast cells (Kondo et al., 2000; Liu et al., 1999; Liu et al., 2000; Trawczyńska and Wójcik, 2014; Trawczyńska et al., 2018; Trawczyńska, 2020a). The best concentration of the solution was determined in the range of $20-60 \%$. In most cases, solutions of ethanol and 2-propanol at the concentration of $40 \%$ or $50 \%$ proved to be the most effective agents (Trawczyńska and Wójcik, 2014, 2015). The optimal concentration of the 1-propanol solution was $20 \%$.

In most cases, the influence of temperature on the chemical permeabilization process proved to be equally important to the concentration of the solution used (Panesar et al. 2007a; Trawczyńska and Wójcik, 2014). This parameter was optimized in the range of 10 to $30^{\circ} \mathrm{C}$, and the results varied significantly. Similar to other techniques used in biotechnology, the permeabilization process is dependent on the time of exposure of yeast cells to permeabilizing agents. Some studies $(\mathrm{Pa}-$ nesar et al. 2007a; Abraham and Bhat, 2008; Liu et al., 1999 ) indicate that the appropriate time of exposure is very short (i.e., $5 \mathrm{~min}$ ) (Flores et al., 1994; Presecki and Vasic-Racki, 2005), while other studies indicate that it is significantly longer (i.e., 250 min) (Upadhya et al., 2000). Generally, the permeabilization process was analyzed in the range from 20 to $60 \mathrm{~min}$ (Panesar et al. 2007a; Trawczyńska and Wójcik, 2014).

\section{Mixtures of chemical permeabilizing agents}

Toluene, an agent used in the permeabilization of S. cerevisiae cells, is slightly soluble in aqueous solutions; hence, the use of toluene alone does not provide satisfactory results (Serrano et al., 1973). To address this problem, dissolving toluene in ethanol or its use in combination with Triton X-100 has been proposed. A mixture of toluene and ethanol in the permeabilization process enhanced the activity of hexokinase and glucose-6-phosphate dehydrogenase when compared to permeabilization with sodium deoxycholate or Triton X-100 or the use of freeze-thaw techniques (Serrano et al., 1973).

S. cerevisiae cells permeabilized with TET (a mixture of toluene, ethanol, and Triton X-100) (Takeshige and Ouchi, 1995) were used in studies aimed at increasing the efficiency of alcoholic fermentation. An analysis of the inhibitory effect of methanol and 1-propanol on alcoholic fermentation showed that the presence of me- thanol slowed down the process in which nonpermeabilized cells were used, whereas permeabilized cells were resistant to the inhibitory effect of methanol. 1Propanol inhibited fermentations with both intact and permeabilized cells. The use of TET in the permeabilization process of $S$. cerevisiae did not provide satisfactory results and caused partial deactivation of enzymes. This has been determined on the basis of the measurement of glucose-6-phosphate dehydrogenase and cytosolic enzyme activities as well as the amount of proteins present in the filtrate (Freire et al., 1998).

\section{Conclusions}

The process of permeabilization of yeast is a very complex one. The conditions of permeabilization have to be determined separately for each species. For this purpose, the effect of many different substances on the permeability of cell walls and membranes should be analyzed. Chemical permeabilization using detergents in comparison to organic solvents causes drastic changes in the cell membrane structure, which consequently causes leakage of the cell contents, leading, at times, to the disintegration of the cell itself. Attempts to prevent this phenomenon have been unsuccessful to date. Therefore, to make the process more economical and feasible for using microorganisms for a second reaction round with the same biocatalyst, it is recommended to use alcohols instead of using detergents in the permeabilization method.

Reactions that use permeabilized yeast cells are comparatively more economical in large-scale processes than those based on the application of pure enzymes or intact cells. This type of biocatalysts offers another advantage of high stability and reduced purification requirement in comparison with a chemical catalysis and purified enzymes. Further development of biocatalysts as permeabilized cells of microorganisms may involve the immobilization or lyophilization method. Future research should focus on the possibilities of using permeabilization to increase the production of not one but several enzymes simultaneously, which will probably positively affect the economic aspects of the bioprocesses analyzed.

\section{Acknowledgments}

The author is thankful to Professor Marek Wójcik for providing valuable comments and feedback at various stages of this research. 


\section{References}

Abraham J., Bhat S.G. (2008) Permeabilization of baker's yeast with N-lauroyl sarcosine. J. Ind. Microbiol. Biotechnol. 35: 799-804.

Alamae T., Jarviste A. (1995) Permeabilization of the methylotrophic yeast Pichia pinus for intracellular enzyme analysis: a quantitative study. J. Microbiol. Meth. 22: 193-205.

Al-Najada A.R., Almulaiky Y.Q., Aldhahri M., El-Shishtawy R.M., Mohamed S.A., Baeshen M., Al-Farga A., Abdulaal W.H., Al-Harbi S.A. (2019) Immobilisation of $\alpha$-amylase on activated amidrazone acrylic fabric: a new approach for the enhancement of enzyme stability and reusability. Sci. Rep. 9: 12672.

Bachhawat N., Gowda L.R., Bhat S.G. (1996) Single step method of preparation of detergent-permeabilized Kluyvero myces fragilis for lactose hydrolysis. Process Biochem. 31: 21-25.

Bankapalli K., Saladi S., Awadia S.S., Goswami A.V., Samaddar M., D'Silva P. (2015) Robust glyoxalase activity of Hsp31, a ThiJ/DJ-1/PfpI family member protein, is critical for oxidative stress resistance in Saccharomyces cerevisiae. J. Biol. Chem. 290: 26491-26507.

Berłowska J., Kregiel D., Klimek L., Orzeszyna B., Ambroziak W. (2006) Novel yeast cell dehydrogenase activity assay in situ. Pol. J. Microbiol. 55: 127-131.

Chelico L., Khachatourians G.G. (2003) Permeabilization of Beauveria bassiana blastospores for in situ enzymatic assays. Mycologia 95: 976-981.

Chen J.C., Naglak T.J., Wang H.Y. (1992) An amperometric alcohol sensor based on chemically permeabilized methylotrophic microorganisms. Biotechnol. Prog. 8: 161-164.

Choi J.E., Shinoda S., Inoue R., Zheng D., Gröger H., Asano Y. (2019) Cyanide-free synthesis of an aromatic nitrile from a biorenewable-based aldoxime: development and application of a recombinant aldoxime dehydratase as a biocatalyst. Biocatal. Biotransfor. 37: 414-420.

Choudary V.P. (1984) A simple micromethod for rapid kinetic analyses of yeast enzymes in situ. Anal. Biochem. 138: 425-429.

Choudary V.P., Rao G.R. (1976) Regulatory properties of yeast nitrate reductase in situ. Can. J. Microbiol. 22: 35-42.

Chow C.K., Palecek S.P. (2004) Enzyme encapsulation in permeabilized Saccharomyces cerevisiae cells. Biotechnol. Prog. 20: 449-456.

Cortez D.V., Roberto I.C. (2010) Permeabilization of Candida guilliermondii cells using chemical and physical processes and their potential use as biocatalysts in the synthesis of xylitol. J. Biotechnol. 150: S376-S376.

Crotti L.B., Drgon T., Cabib E. (2001) Yeast cell permeabilization by osmotic shock allows determination of enzymatic activities in situ. Anal. Biochem. 292: 8-16.

DiCosimo R., McAuliffe J., Poulose A.J., Bohlmann G. (2013) Industrial use of immobilized enzymes. Chem. Soc. Rev. 42: 6437-6474.

Esteves A.C., Saraiva M., Correia A., Alves A. (2014) Botryosphaeriales fungi produce extracellular enzymes with biotechnological potential. Can. J. Microbiol. 60: 332-342.
Fenton D.M. (1982) Solvent treatment for $\beta$-D-galactosidase release from yeast cells. Enzyme Microb. Technol. 4: 229-232.

Flores M.V., Voget C.E., Ertola R.J.J. (1994) Permeabilization of yeast cells (Kluyveromyces lactis) with organic solvents, Enzyme Microb. Technol. 16: 340-346.

Fontes E.A.F., Passos F.M.L., Passos F.J.V. (2001) A mechanistical mathematical model to predict lactose hydrolysis by $\beta$-galactosidase in a permeabilized cell mass of Kluyveromyces lactis: validity and sensitivity analysis. Process Biochem. 37: 267-274.

Freire A.P., Martins A.M., Cordeiro C. (1998) A practical experiment on cell permeabilization and biochemical characterisationin situ. Biochem Educ. 26: 66-68.

Galabova D., Tuleva B., Spasova D. (1996) Permeabilization of Yarrowia lipolytica cells by Triton X-100. Enzyme Microb. Tech. 18: 18-22.

Ge S., Ge S., Zhou M., Dong X. (2015) Bioremediation of hexavalent chromate using permeabilized Brevibacterium $s p$. and Stenotrophomonas sp. cells. J. Environ. Manage. 157: 54-59.

Gough S., Deshpande M., Scher M., Rosazza J.P.N. (2001) Permeabilization of Pichia pastoris for glycolate oxidase activity. Biotechnol. Lett. 23: 1535-1537.

Gowda L.R., Bachhawat N., Bhat S.G. (1991) Permeabilization of Bakers' yeast by cetyltrimethylammonium bromide for intracellular enzyme catalysis. Enzyme Microb. Technol. 13: 154-157.

Greiling A.M., Tschesche C., Baardsen G., Kröckel S., Koppe W., Rodehutscord M. (2019) Effects of phosphate and phytase supplementation on phytate degradation in rainbow trout (Oncorhynchus mykiss W.) and Atlantic salmon (Salmo salar L.) Aquaculture 503: 467-474.

Handa-Corrigan A., Zhang S., Brydges R. (1992) Surface-active agents in animal cell cultures. [in:] Animal cell biotechnology. Ed. Spier R.E., Griffiths J.B. Academic Press, London: 279-301.

He Y., Sun W.T., Wang S.C., Reed P.A.S., Walsh F.C. (2017) An electrodeposited Ni-P-WS2 coating with combined super-hydrophobicity and self-lubricating properties. Electrochim. Acta 245: 872-882.

He Y.C., Zhang Z.J., Xu J.H., Liu Y.Y. (2010) Biocatalytic synthesis of $(R)-(-)$-mandelic acid from racemic mandelonitrile by cetyltrimethylammonium bromide permeabilized cells of Alcaligenes faecalis ECU0401. J. Ind. Microbiol. Biotechnol. 37: 741-750.

Homola P., Kurák T., Illeová V., Polakovič M. (2015) Kinetics of acetophenone reduction to (R)-1-phenylethanol by a whole-cell Pichia capsulata biocatalyst. Biocatal. Biotransfor. 33: 323-332.

Joshi M.S., Gowda L.R., Bhat S.G. (1987) Permeabilization of yeast cells (Kluyveromyces fragilis) to lactose by cetyltrimethylammonium bromide. Biotechnol. Lett. 9: 549-554.

Joshi M.S., Gowda L.R., Katwa L.C., Bhat S.G. (1989) Permeabilization of yeast cells (Kluyveromyces fragilis) to lactose by digitonin. Enzyme Microb. Technol. 11: 439-443. 
Joshi S., Satyanarayana T. (2014) Optimization of heterologous expression of the phytase (PPHY) of Pichia anomala in $P$. pastoris and its applicability in fractionating allergenic glycinin from soy protein. J. Ind. Microbiol. Biotechnol. 41: 977-987.

Karnwal A., Singh S., Kumar V. Sidhu G.K., Dhanjal D.S., Datta S., Amin D.S., Saini M., Singh J. (2019) Fungal Enzymes for the Textile Industry. [in:] Recent advancement in white biotechnology through fungi. Ed. Yadav A., Mishra S., Singh S., Gupta A. Fungal Biology. Springer, Cham: 459-482.

Kaur G., Panesar P.S., Bera M.B., Kumar H. (2009) Hydrolysis of whey lactose using CTAB-permeabilized yeast cells. Bioprocess Biosyst. Eng. 32: 63-67.

Kaur P., Satyanarayana T. (2010) Improvement in cell-bound phytase activity of Pichia anomala by permeabilization and applicability of permeabilized cells in soymilk dephytinization. J. Appl. Microbiol. 108: 2041-2049.

King A.T., Davey M.R., Mellor I.R., Mulligan B.J., Lowe K.C. (1991) Surfactant effects on yeast cells. Enzyme Microb. Technol. 13: 148-153.

Kinosita Y., Miyata M., Nishizaka T. (2018) Linear motor driven-rotary motion of a membrane-permeabilized ghost in Mycoplasma mobile. Sci. Rep. 8: 11513.

Kippert F. (1995) A rapid permeabilization procedure for accurate quantitative determination of beta-galactosidase activity in yeast cells. FEMS Microbiol. Lett. 128: 201-206.

Koley D., Bard A.J. (2010) Triton X-100 concentration effects on membrane permeability of a single HeLa cell by scanning electrochemical microscopy (SECM). Proc. Natl. Acad. Sci. USA. 107: 16783-16787.

Kondo A., Liu Y., Furuta M., Fujita Y., Matsumoto T., Fukuda H. (2000) Preparation of high activity whole cell biocatalyst by permeabilization of recombinant flocculent yeast with alcohol. Enzyme Microb. Technol. 27: 806-811.

Kostova D.D., Petrova V.Y., Kujumdzieva A.V. (2008) Overexpression of DAAO and catalase in Kluyveromyces marxianus through media optimization, permeabilization and GA stabilization techniques. Enzyme Microb. Technol. 42: 113-120.

Kumari S., Panesar P.S., Bera M.B., Singh B. (2011) Permeabilization of yeast cells for beta-galactosidase activity using mixture of organic solvents: a response surface methodology approach. Asian J. Biotechnol. 3: 406-414.

Laouar L., Lowe K.C., Mulligan B.J. (1996) Yeast responses to nonionic surfactants. Enzyme Microb. Tech. 18: 433-438.

Lee Y.J., Kim C.S., Oh D.K. (2004) Lactulose production by $\beta$-galactosidase in permeabilized cells of Kluyveromyces lactis. Appl. Mikrob. Biotechnol. 64: 787-793.

Liu D., Ding L., Sun J., Boussetta N., Vorobiev E. (2016) Yeast cell disruption strategies for recovery of intracellular bioactive compounds-A review. Innovat. Food Sci. Emerg. Technol. 36: 181-192.

Liu J.,Wang Q.L., Chang Q., Han L.N., Pei G.L., Xue Y.Q., Jia L.M., Zhang K., Duan Y.Y., Kang Z. (2014) Isocitrate lyase is required for urediniospore germination of Puccinia striiformis f. sp. tritici. Mol. Biol. Rep. 41: 7797-7806.
Liu Y., Fujita Y., Kondo A., Fukuda H. (2000) Preparation of high-activity whole cell biocatalysts by permeabilization of recombinant yeasts with alcohol. J. Biosci. Bioeng. 89: 554-558.

Liu Y., Hama H., Fujita Y., Kondo A., Inoue Y., Kimura A., Fukuda H. (1999) Production of S-lactoylglutathione by high activity whole cell biocatalysts prepared by permeabilization of recombinant Saccharomyces cerevisiae with alcohols. Biotechnol. Bioeng. 64: 54-60.

Llombart P., Palafox M.A., MacDowell L.G., Noya E.G. (2019) Structural transitions and bilayer formation of CTAB aggregates. Colloids Surf. A Physicochem. Eng. Asp. 580: 123730

Loew O. (1901) Catalase, a new enzyme of general occurrence, with special reference to the tobacco plant. U. S. Dept. Agr. Rpt. 68: 47.

Lowe K.C., Davey M.R., Power J.B., Mulligan B.J. (1993) Surfactant supplements in plant culture systems. Agro Food Industry Hi Tech 4: 9-13.

Manocha B., Gaikar V.G. (2006) Permeabilization of Aspergillus niger by reverse micellar solutions and simultaneous purification of catalase. Separ. Sci. Technol. 41: 3279-3296.

Matsuzaki K. (2019) Membrane permeabilization mechanisms. [in:] Antimicrobial peptides. Advances in Experimental Medicine and Biology, vol 1117. Ed. Matsuzaki K. Springer, Singapore.

Mattei B., Lira R.B. Perez K.R. Riske K.A. (2017) Membrane permeabilization induced by Triton $X$-100: the role of membrane phase state and edge tension. Chem. Phys. Lipids 202: 28-37.

Mesina V.G.R., Lagos L.V., Sulabo R.C., Walk C.L., Stein HH. (2019) Effects of microbial phytase on mucin synthesis, gastric protein hydrolysis, and degradation of phytate along the gastrointestinal tract of growing pigs. J. Anim. Sci. 97: 756-767.

Naglak T.J., Wangt H.Y. (1992) Rapid protein release from Escherichia coli by chemical permeabilization under fermentation conditions. Biotechnol. Bioeng. 39: 732-740.

Nayak C.A., Suguna K., Rastogi N.K. (2006) Combined effect of gammairradiation and osmotic treatment on mass transfer during rehydration of carrots. J. Food Eng. 74: 134-142.

Nigam P.S. (2013) Microbial enzymes with special characteristics for biotechnological applications. Biomolecules 3: 597-611.

Norouzian D., Akbarzadeh A., Inanlou D.N., Farahmand B., Saleh M., Sheikh-ul-Eslam F., Vaez J. (2003) Biotransformation of alcohols to aldehydes by immobilized cells of Saccharomyces cerevisiae PTCC5080. Enzyme Microb. Tech. 33: 150-153.

Noubhani A., Bunoust O., Rigoulet M., Thevelein J.M. (2000) Reconstitution of ethanolic fermentation in permeabilized spheroplasts of wild-type and trehalose-6-phosphate synthase mutants of the yeast Saccharomyces cerevisiae. Eur. J. Biochem. 267: 4566-4576.

Novickij V., Lastauskiene E., Svediene J., Grainys A., Staigvila G., Paskevicius A., Girkontaite I., Zinkeviciene A., Markovskaja S., Novickij J. (2018) Membrane permeabilization 
of pathogenic yeast in alternating sub-microsecond electromagnetic fields in combination with conventional electroporation. J. Membr. Biol. 251: 189-195.

Olczak I., Grubecki I., Wójcik M. (2010) Optimization of the permeabilization process of Saccharomyces cerevisiae yeast cells using methanol. Chem. Eng. Equip. 49: 89-90.

Panduric N., Salic A., Zelic B. (2017) Fully integrated biotransformation of Fumaric acid by permeabilized Baker's yeast cells with in situ separation of L-malic acid using ultrafiltration, acidification and electrodialysis. Biochem. Eng. J. 125: 221-229.

Panesar P.S., Panesar R., Singh R.S., Bera M.B. (2007a) Permeabilization of yeast yells with organic solvents for $\beta$-galactosidase activity. Res. J. Microbiol. 2: 34-41.

Panesar R., Panesar P.S., Singh R.S., Kennedy J.F., Bera M.B. (2007b) Production of lactose-hydrolyzed milk using ethanol permeabilized yeast cells. Food Chem. 101: 786-790.

Panesar R., Panesar P.S., Singh R.S., Kennedy J.F. (2011) Hydrolysis of milk lactose in a packed bed reactor system using immobilized yeast cells. J. Chem. Technol. Biot. 86: 42-46.

Panwar D., Kaira G.S., Kapoor M. (2017) Cross-linked enzyme aggregates (CLEAs) and magnetic nanocomposite grafted CLEAs of GH26 endo-beta-1,4-mannanase: improved activity, stability and reusability. Int. J. Biol. Macromol. 105: 1289-1299.

Papoutsakis E.T. (1991) Fluid mechanical damage of animal cells in bioreactors. Trends Biotechnol. 9: 427-437.

Presecki A.V., Vasic-Racki D. (2005) Production of L-malic acid by permeabilized cells of commercial Saccharomyces sp. strains. Biotechnol Lett. 27: 1835-1839.

Presecki A.V., Zelić B., Vasić-Racki D. (2007) Comparison of the L-malic acid production by isolated fumarase and fumarase in permeabilized baker's yeast cells. Enzyme Microb. Technol. 41: 605-612.

Rajagopal K., Singh P.K., Kumar R., Siddiqui K.F. (2014) CTAB-mediated, single-step preparation of competent Escherichia coli, Bifidobacterium sp. and Kluyveromyces lactis cells. Meta Gene 2: 807-818.

Rodriguez-Colinas B., de Abreu M.A., Fernandez-Arrojo L., de Beer R., Poveda A., Jimenez-Barbero J., Haltrich D., Ballesteros Olmo A.O., Fernandez-Lobato M., Plou F.J. (2011) Production of Galacto-oligosaccharides by the $\beta$-galactosidase from Kluyveromyces lactis: comparative analysis of permeabilized cells versus soluble enzyme. J. Agric. Food Chem. 59: 10477-10484.

Rosinha Grundtvig I.P., Heintz S., Krühne U., Gernaey K.V., Adlercreutz P., Hayler J.D., Wells A.S., Woodley J.M. (2018) Screening of organic solvents for bioprocesses using aqueous-organic two-phase systems. Biotechnol. Adv. 36: 1801-1814.

Seip J.E., Di Cosimo R. (1992) Optimization of accessible catalase activity in polyacrylamide gel-immobilized Saccharomyces cerevisiae. Biotechnol. Bioeng. 40: 638-642.

Sekhar S., Bhat N., Bhat S.G. (1999) Preparation of detergent permeabilized Bakers' yeast whole cell catalase. Proc.
Biochem. 34: 349-354.

Serrano R., Gancedo J.M., Gancedo C. (1973) Assay of yeast enzymes in situ: a potential tool in regulation studies. Eur. J. Biochem. 34: 479-482.

Sestak S., Farkas V. (2001) In situ assays of fungal enzymes in cells permeabilized by osmotic shock. Anal. Biochem. 292: 34-39.

Shin K.C., Sim D.H., Seo M.J., Oh D.K. (2016) Increased production of food-grade d-tagatose from d-galactose by permeabilized and immobilized cells of Corynebacterium lutamicum, a GRAS host, expressing d-galactose isomerase from Geobacillus thermodenitrifcans. J. Agric. Food Chem. 64: 8146-53.

Sommerfeld V., Kessel A.G., Classen H.L., Schollenberger M., Kühn I., Rodehutscord M. (2019) Phytate degradation in gnotobiotic broiler chickens and effects of dietary supplements of phosphorus, calcium, and phytase. Poult. Sci. 98: 5562-5570.

Stirke A., Zimkus A., Ramanaviciene A., Balevicius S., Zurauskiene N., Saulis G., Chaustova L., Stankevic V., Ramanavicius A. (2014) Electric field-induced effects on yeast cell wall permeabilization. Bioelectromagnetics 35: 136-144.

Takatsume Y., Izawa S., Inoue Y. (2004) Identification of thermostable glyoxalase $I$ in the fission yeast Schizosaccharomyces pombe. Arch. Microbiol, 181: 371-377.

Takeshige K., Ouchi K. (1995) Reconstruction of ethanol fermentation in permeabilized cells of the yeast Saccharomyces cerevisiae. J. Ferment. Bioeng. 79: 11-16.

Tan Q., Song Q., Zhang Y., Wei D. (2007) Characterization and application of D-amino acid oxidase and catalase within permeabilized Pichia pastoris cells in bioconversions. Appl. Biochem. Biotechnol. 136: 279-290.

Tan Q., Zhang Y., Wie D. (2011) Characterization and stability of D-amino acid oxidase and catalase within the permeabilized recombinant Pichia pastoris cells. Afr. J. Biotechnol. 10: 19153-19160.

Teissie J., Golzio M., Rols M.P. (2005) Mechanisms of cell membrane electropermeabilization: a minireview of our present (lack of ?) knowledge. Biochim. Biophys. Acta 1724: 270-280.

Tozlu C., Sahin E., Serencam H., Dertli E. (2019) Production of enantiomerically enriched chiral carbinols using Weissella paramesenteroides as a novel whole cell biocatalyst. Biocatal. Biotransfor. 37: 388-398.

Trawczyńska I. (2019) Immobilization of permeabilized cells of baker's yeast for decomposition of $\mathrm{H}_{2} \mathrm{O}_{2}$ by catalase. Pol. J. Chem. Technol. 21: 59-63.

Trawczyńska I. (2020a) Optimization of the production conditions of biocatalyst for decomposition of hydrogen peroxide. Przem. Chem. 99: 617-619.

Trawczyńska I. (2020b) Permeabilized and immobilized yeast cells as a biocatalyst of hydrogen peroxide decomposition. Przem. Chem. 99: 439-441.

Trawczyńska I., Miłek J., Kwiatkowska-Marks S. (2018) Effect of temperature, concentration of alcohols and time on baker's yeast permeabilization process. Technical Sci. 21: 
195-206.

Trawczyńska I., Wójcik M. (2014) Application of Response Surface Methodology for optimization of permeabilization process of baker's yeast. Pol. J. Chem. Technol. 16:31-35.

Trawczyńska I., Wójcik M. (2015) Optimization of permeabilization process of yeast cells for catalase activity using response surface methodology. Biotechnol. Biotechnol. Equip. 29: 72-77.

Upadhya R., Bhat N., Bhat S.G. (2000) Stabilization of $D$ amino acid oxidase and catalase in permeabilized Rhodotorula gracilis cells and it's application for the preparation of alpha-ketoacids. Biotechnol. Bioeng. 68: 430-436.

Upadhya R., Nagajyothi H., Bhat S.G. (1999) D-Amino acid oxidase and catalase of detergent permeabilized Rhodotorula gracilis cells and its potential use for the synthesis of alpha-keto acids. Process Biochem. 35: 7-13.

Venkateshwaran G., Somashekar D., Prakash M.H., Agrawal R., Basappa S.C., Joseph R. (1999) Production and utilization of catalase using Saccharomyces cerevisiae. Process Biochem. 34: 187-191.

Villa F., Cappitelli F., Principi P., Polo A., Sorlini C. (2009) Permeabilization method for in-situ investigation of fungal conidia on surfaces. Lett. Appl. Microbiol., 48: 234-240.

Voget C.E. (2018) Recovery of B-galactosidase from the yeast Kluyveromyces lactis by cell permeabilization with sarkosyl. Process Biochem. 75: 250-256.

Wang L., Sha Y., Wu D., Wei Q., Chen D., Yang S., Jia F., Yuan Q., Han X., Wang J. (2019) Surfactant induces ROS-media- ted cell membrane permeabilization for the enhancement of mannatide production. Process Biochem. [in press]

Yadav J.S., Bezawada J., Yan S., Tyagi R.D., Surampalli R.Y. (2014) Permeabilization of Kluyveromyces marxianus with mild detergent for whey lactose hydrolysis and augmentation of mixed culture. Appl. Biochem. Biotechnol. 172: 3207-3222.

Yan Q., Machalz D., Zollner A., Sorensen E.J., Wolber G., Bureik M. (2017) Efficient substrate screening and inhibitor testing of human CYP4Z1 using permeabilized recombinant fission yeast Biochem. Pharmacol., 146: 174-187.

Yu M.A., Wei Y.M., Zhao L., Jiang L., Zhu X.B., Qi W. (2007) Bioconversion of ethyl 4-chloro-3-oxobutanoate by permeabilized fresh brewer's yeast cells in the presence of allyl bromide. J. Ind. Microbiol. Biotechnol. 34: 151-156.

Zhenxiao Y., Hongchen Z., Xingya Z., Shufang L., Jianyong X., Hui S. (2016) High level extracellular production of a recombinant alkaline catalase in E. coli BL21 under ethanol stress and its application in hydrogen peroxide removal after cotton fabrics bleaching Bioresour. Technol. 214: 303-310.

Zlotnik H., Fernandez M.P., Bowers B., Cabib E. (1984) Saccharomyces cerevisiae mannoproteins form an external cell wall layer that determines wall porosity. J. Bacteriol. 159: 1018-1026. 